\title{
Research on Innovative Personnel Training System of Measurement and Control Specialty under the Background of Engineering Education Professional Certification
}

\author{
Dexin Xu, Yuxin Zhao, Xuemei Zhou, Ning Li \\ Automation College, Harbin Engineering University, Harbin, China \\ Email: xudexin@hrbeu.edu.cn, zhaoyuxin@hrbeu.edu.cn, zhouxuemei@hrbeu.edu.cn, lining@hrbeu.edu.cn
}

How to cite this paper: $\mathrm{Xu}, \mathrm{D}$. X., Zhao, Y. X., Zhou, X. M., \& Li, N. (2020). Research on Innovative Personnel Training System of Measurement and Control Specialty under the Background of Engineering Education Professional Certification. Open Journal of Social Sciences, 8, 205-216.

https://doi.org/10.4236/jss.2020.83018

Received: October 30, 2019

Accepted: March 17, 2020

Published: March 20, 2020

\begin{abstract}
This paper first discusses the problems existing in the innovative personnel training system under the background of engineering education certification, and then analyzes the research approaches and methods of the "innovative" personnel training system of measurement and control specialty. Finally, combined with the characteristics of the specialty and the background of the current engineering education specialty, it focuses on the analysis of the relationship between the industry and social needs and the target concept system, the curriculum module and the key elements of graduation requirements. On the basis of discussing how to build the supporting conditions and continuous improvement mechanism of innovation and entrepreneurship and practical education, this paper puts forward how to build the "innovative" talent training system which is composed of four parts: the target concept system, the training implementation system, the training support system and the continuous improvement system.
\end{abstract}

\section{Keywords}

Measurement and Control Technology and Instrument, Innovative, Four in One, Personnel Training System, Professional Certification of Engineering Education

\section{Introduction}

In June 2017, the "measurement and control technology and instrument" major of automation college of Harbin University of Engineering passed the entrance examination of engineering education professional certification experts. Com- 
bined with the development of engineering education certification, it has become an important topic to explore how to build a scientific and reasonable innovative talent training system and continuous improvement. The major of "measurement and control technology and instrument" is a national specialty, a key specialty of the Ministry of industry and information technology, the first major of automation college to be selected into the "excellent engineer education and training plan" of the Ministry of education, and the first major to apply for engineering education professional certification. For many years, the major has attached great importance to the cultivation of students' innovation ability. In the past three years, the students of the major have participated in 433 scientific and technological innovation activities and won 410 scientific and technological awards.

Measurement and control technology and instrument specialty are mainly for the fields of instruments, detection technology, measurement and control technology, and play a very important role in the development of national economy. The design of talent training system directly determines the achievement of talent training objectives, is the overall design of talent training objectives, training programs, training modes and training processes, and is the decisive factor to ensure the quality of talent training. Taking the measurement and control technology and instrument specialty of Harbin University of engineering as an example, this paper aims at the characteristics of measurement and control technology and instrument specialty under the background of engineering education certification, as well as the current social demand for high-quality measurement and control talents, to carry out the research of innovative talents training program, and explore how to cultivate high-quality innovative measurement and control technology outstanding engineers and high-end technical talents.

\section{Current Problems}

Through the discussion and research in many brother colleges and universities, and through the summary, there are the following problems in China's innovative talent training system:

1) Many domestic scholars have conducted a series of researches on the "innovative" talent training system, but most of them are limited to literature research and theoretical research, and fail to focus on the feedback and continuous improvement of the implementation process (Qi, 2016: p. 14).

2) Due to the differences in system, humanities and social environment between domestic and foreign universities, the construction of talent training system in domestic universities cannot be simply copied (Liu et al., 2014: p. 40). In addition, colleges and universities have their own characteristics in specialty setting, training objectives and so on. If we do not consider this problem, it will inevitably be out of line with the actual situation.

3) "Innovative" personnel training mode has not been fundamentally established. (Li et al., 2013: p. 138) Although innovation has gradually become an important indicator of talent training objectives, various policies, systems and 
measures are constantly introduced, most of which are only partial amendments and supplements on the basis of the traditional training mode, and have not played a significant role in the "innovative" talent training.

4) The establishment of the "innovative" talent training system has not been effectively combined with the current assessment and certification work, the goal oriented mechanism is insufficient, and there is not a complete set of systematic links such as the training objectives, curriculum system, training platform, and comprehensive evaluation for the "innovative" talent training effectively closed-loop operation. (Chen, 2018: p. 12) (Wang \& Sun 2017: p. 168)

5) The supporting system of innovative personnel training is insufficient, and the management system, incentive measures, teaching staff and innovation platform need to be further strengthened. (Wu, 2016: p. 149) (Xie, 2011: pp. 217-221) The current performance appraisal management mechanism leads to the fact that teachers pay more attention to scientific research than teaching.

\section{Research Approaches and Methods}

The research of "innovative" talent training system is based on years of practice. The implementation plan and method are as follows:

1) Investigate the demand and current situation of "innovative" talents, query relevant literature and cases at home and abroad, and put forward the training specifications, quality requirements and evaluation standards of "innovative" talents from the perspective of employers such as enterprises and companies (Wang, 2017: pp. 69-70).

2) Change the education concept, optimize the training objectives, carry out the connotation analysis and research of "innovative" personnel training, confirm the goal orientation of "student center" and "ability training" (Yin, 2015: pp. 75-77), and realize the determination of the training objectives in combination with the professional positioning, social needs and professional characteristics of the school.

3) Investigate the students of this major, investigate the training objectives, innovation ability training, teaching mode, teaching means, condition construction, etc., and study an acceptable and expected training mode from the perspective of students, so that students can design their own development direction according to their own interests, hobbies and wishes (Shen et al., 2018: p. 143).

4) To investigate the implementers of "innovative" talent training, i.e. teachers and instructors, and listen to teachers' suggestions on the curriculum system, practical teaching system, quality assurance system, safeguard mechanism and incentive policy of "innovative" talent training.

5) Carry out investigation, study and Research on brother colleges and universities, and fully absorb the educational concept and successful experience of "innovative" talent training in brother colleges and universities.

6) Summarize and analyze the effect of innovation education implemented in our university, especially in automation college for many years.

7) Based on the existing basis and research feedback, learning and reference, 
the implementation system of "innovative" talent training is studied theoretically, and the contents of curriculum system, teaching mode, teaching means, practical teaching, teaching assessment and evaluation, teaching management mode and quality monitoring system are studied comprehensively by using system theory and methodology.

8) Carry out the research on the supporting system of "innovative" personnel training, comprehensively study the construction of the second classroom, supporting conditions, teaching staff and innovation platform, and put forward and improve the planning, mechanism, safeguard measures and incentive policies of "innovative" personnel training.

9) Hold a special seminar on "innovative" talent training system for measurement and control technology and instrument specialty, and adjust and implement important mechanisms and policies related to system construction.

10) Carry out project research in combination with the actual work, pilot the phased research results of the project, summarize and analyze the pilot results, and further improve the research results on this basis.

\section{The Construction of "Innovative" Personnel Training System}

According to the concept of the above research approaches and methods, combined with the actual situation of measurement and control major and the background of engineering education major certification, the "innovative" talent training system is established, which is composed of four parts: the goal concept system, the training implementation system, the training support system and the continuous improvement system.

\subsection{Target Concept System}

The training objectives of this major meet the needs of social and economic development, conform to the positioning of high-level research university of the University, and the history and tradition of training senior engineering and technical personnel for the national defense fields such as ship, aerospace, aviation, weapons, etc. for many years, with the inertial navigation and measurement and control technology as the professional characteristics.

This major is committed to cultivating professional technical knowledge with engineering science foundation, general sensing, detection and control, instrument design and application, theoretical analysis and engineering practice experience of inertial navigation and measurement and control technology, ability to analyze, research and solve complex engineering problems, ability to organize management, cooperation and exchange, and independent learning, innovative consciousness and society. Sense of responsibility, professional ethics and humanistic quality, high-quality talents who can engage in scientific research, technological development, quality control and production management in measurement control and instruments and related fields.

This major is oriented to the industry of inertial navigation and measurement 
and control technology, serving the fields of national defense, industry and information, training applied talents of measurement and control technology and instruments, and focusing on training specialized talents of inertial navigation and measurement and control technology. This is in line with the school's orientation of "serving national industrialization, informatization, national defense and marine modernization".

This major is developed from "hydrographic survey" major and "gyro navigation equipment" major of Harbin military engineering college. Through courses with various technical backgrounds of light, machine, electricity, automatic control technology, computer technology and information technology, in addition to training high-level engineering talents in the field of inertial navigation, it also takes into account the training of general measurement and control technology talents. Measurement and control technology and instruments, involving all sectors of the national economy, are widely used majors with a large talent demand market. With the development of knowledge economy represented by electronic technology and information technology, the demand for measurement and control technology and instrument discipline professionals will further increase. In the new domestic and international environment, the Chinese government has put forward the "made in China 2025" plan in recent years, which focuses on improving the innovation ability and development quality of the manufacturing industry. The innovation and development of measurement and control technology and instrument technology will undoubtedly become an important driving force for the future intelligent manufacturing industry. In addition, at present, Heilongjiang province puts forward the development strategy of accelerating the revitalization of the old industrial base. In order to help the transformation and upgrading of Heilongjiang industry, it is necessary to do a good job in personnel training for this major, and to do a good job in talent reserve for the economic and technological revitalization of Heilongjiang.

\subsection{Training Implementation System}

The "innovative" talent training implementation system of this major is mainly composed of implementation and construction system and guarantee system. The implementation and construction system includes teaching mode and curriculum construction, curriculum system and teaching material construction, teaching means and assessment, practical teaching system and experimental training base construction. The guarantee system mainly includes teaching management mode and quality assurance system.

This major has strong support ability of scientific research strength, and the average scientific research funds of teachers are the first in the University, ranking in the forefront of domestic disciplines. Therefore, in combination with the vertical and horizontal scientific research tasks undertaken by the teachers of this major, we should focus on "scientific research for teaching" and "scientific research back feeding teaching". We should apply the contents of scientific re- 
search achievements for many years to the course construction, write the contents of scientific research achievements into the teaching materials, incorporate the contents of scientific research experiments into the experimental contents, and build the experimental training base in scientific research cooperation units. A number of monographs and teaching materials related to scientific research have been published, and a number of joint training bases for research institutes of Aerospace Science and technology group, aerospace science and technology group and China Shipbuilding Heavy Industry Group have been established to carry out experimental training activities. In terms of teaching methods, in addition to the traditional teaching methods, it is required to arrange special class hours for key courses, and add interactive and discussion teaching between teachers and students, students and students. In addition, in the form of curriculum assessment, exercises, major assignments (Experiments) and cumulative examination are carried out. Fully reflect "student-centered", through "students' actual knowledge acquisition" to ensure the quality of teaching.

The measurement and control technology and instrument major is under the discipline of Instrument Science and technology, with the professional background of inertial technology as the core. Inertial technology belongs to the category of control science and engineering at the same time. Therefore, this major has the characteristics of both Instrument Science and control science. The course system of this major is composed of professional basis, professional core, professional courses and professional elective courses related to control and instrument, so that students can master the professional knowledge from device to system, from measurement and control to instrument. At the same time, through the training of practical teaching, the combination of theory and practice is realized.

The curriculum system is the implementation link of talent training. The commonly adopted approach is divided into theoretical curriculum system and practical curriculum system. In order to highlight the cultivation of students' innovation ability, the importance of practical curriculum system is self-evident. Therefore, in the course system design, if the two parts of the system can be organically combined to achieve a smooth transition between theory and practice, it is an effective way.

Table 1 shows the corresponding relationship between the course module and the key elements "complex engineering problems" solution ability and "non-technical factors" ability training of graduation requirements. Due to the emphasis on theoretical courses in the past, students generally lack the practical ability, and the practical content of general courses generally takes the form of in class experiments. However, there are some disadvantages in the training of practical ability only through in class experiments, such as insufficient class hours, repeated experimental contents of similar courses, unable to systematize experimental contents, decentralized forms and so on.

In order to cultivate students' innovative practice ability, on the basis of merging and improving the in class experiments, the professional curriculum 
Table 1. The corresponding relationship between curriculum modules and key elements of graduation requirements.

\begin{tabular}{|c|c|c|c|}
\hline Number & $\begin{array}{l}\text { Curriculum } \\
\text { module }\end{array}$ & Ability training of solving complex engineering problems & Ability cultivation considering non-technical factors \\
\hline 1 & $\begin{array}{l}\text { Foundation } \\
\text { class }\end{array}$ & $\begin{array}{l}\text { Be able to apply multi-disciplinary knowledge and its } \\
\text { basic principles, select and use appropriate modern tools, } \\
\text { and systematically identify, research, express, analyze } \\
\text { and solve complex engineering problems. }\end{array}$ & $\begin{array}{l}\text { Have the ability to learn and adapt to the development of } \\
\text { inertial navigation and measurement and control } \\
\text { technology. }\end{array}$ \\
\hline 2 & $\begin{array}{l}\text { Professional } \\
\text { category }\end{array}$ & $\begin{array}{l}\text { Be able to research, design, develop, evaluate and } \\
\text { implement complex engineering systems innovatively. }\end{array}$ & $\begin{array}{l}\text { The social responsibility consciousness of the feasibility } \\
\text { analysis and social impact of complex engineering } \\
\text { solutions, the consciousness of environmental protection } \\
\text { and sustainable development, the ability of } \\
\text { communication and communication, the ability of } \\
\text { engineering management and economic decision-making, } \\
\text { the ability of independent learning and lifelong learning. }\end{array}$ \\
\hline 3 & $\begin{array}{l}\text { engineering } \\
\text { practice }\end{array}$ & $\begin{array}{l}\text { To cultivate students' ability of complex engineering } \\
\text { system design and development, modern tool } \\
\text { application, engineering practice and innovation. }\end{array}$ & $\begin{array}{l}\text { The ability to analyze the feasibility of solutions to } \\
\text { complex engineering problems and the social } \\
\text { responsibility consciousness of social impact, the } \\
\text { consciousness of environmental protection and sustainable } \\
\text { development, the professional quality of engineers, the } \\
\text { ability of organization and management, the ability of } \\
\text { teamwork and cooperation, the ability of communication } \\
\text { and exchange, the ability of project management, and the } \\
\text { ability of lifelong learning. }\end{array}$ \\
\hline 4 & Dissertation & $\begin{array}{l}\text { To cultivate the students' ability of literature research } \\
\text { and experimental analysis, engineering consciousness, } \\
\text { cooperation spirit and the ability of comprehensive } \\
\text { application of the knowledge learned to solve practical } \\
\text { problems. }\end{array}$ & $\begin{array}{l}\text { Ability of organization and management, team } \\
\text { cooperation and communication. }\end{array}$ \\
\hline
\end{tabular}

modules of this major adopt "four stage" ladder training, namely "professional theory course", "innovative cognition and practice", "curriculum design" and "graduation design". The specific contents are as follows: the professional theory course mainly refers to the professional core course with gyro, accelerometer inertial devices and strapdown inertial navigation system as the content, which also belongs to the characteristic course of this major. "Innovation Cognition and practice" aims to enhance students' innovation consciousness, cultivate students' innovation ability, establish team spirit and improve students' innovation level. Students will gradually master the composition principle of software and hardware, design method, debugging method and the complete development process of an innovative work through personal practice and under the guidance of teachers in class time, so as to make students familiar with the procedures and methods of scientific research and technological innovation as soon as possible, aiming to improve students' comprehensive knowledge of interdisciplinary subjects such as electronics, electricity, detection, control, machinery, etc. The ability of cognition and application lays a foundation for participating in scientific research and various scientific and technological innovation activities in the future. Through the training of this course, the students are mainly trained in the 
ability of preliminary circuit design and embedded software development. "Course design" is to design a small system with professional characteristics on the basis of learning professional basic knowledge and innovative cognition and practice, such as completing data acquisition and processing of gyroscope and accelerometer, outputting navigation information data, or designing the receiving circuit of GPS data, completing the analysis and calculation of navigation data. In the "graduation design" stage, combined with the professional training objectives, with the technical application in a certain direction in the field of this major as the topic, comprehensive application of the knowledge learned, design and analysis from the system simulation to the realization of the system software and hardware, make full use of modern tools and software, based on the professional core curriculum theory, carry out literature research and experimental analysis, and carry out team cooperation. According to the simulation data and experimental data, the effective conclusions are drawn.

\subsection{Training Support System}

The "innovative" talent training support system of this major is mainly composed of support construction system and support guarantee system. The support construction system includes the second classroom construction, support condition construction, Faculty Construction and innovation platform construction. The support guarantee system mainly includes planning, mechanism, guarantee, incentive and policy.

With students as the center, make full use of information construction to realize orderly communication and exchange of information, strengthen the construction of publicity media platform, through the website media such as engineering network, Youth League Committee Qihang network, home page of automation college, new media such as wechat platform, Sina Weibo, Tencent Weibo, myouth, renren.com, youth campus, Heilongjiang workers' daily, annual report of automation college, etc. Paper media enables students to master the information related to the training support system in time. Up to now, the wechat platform of the college has paid close attention to 8504, with a total of more than 250,000 views. It has built a new position of brand promotion, interactive communication and information service of the college and department, and gradually realized the transformation of campus culture construction from substantiation to network coverage.

In terms of innovation and entrepreneurship, we carried out activities such as sailing, science and technology carnival, science and technology innovation salon, science and technology innovation forum, and supported activities of science and technology communities, including more than 60 core members of "Chuangyi science and technology society", more than 2000 members in total, more than 400 awards, more than 40 scientific papers and more than 500 achievements of innovation projects. The measures for awarding the guidance teachers of innovation and entrepreneurship competition for college students of automation college and the training plan for the technological innovation ad- 
vantage project for college students of automation college were promulgated.

In terms of practical education, the college's volunteer service team is led by the new heading volunteer service team with 18 years of military industry inheritance, with the class and League branch as the unit, and has branches such as "V love service team" and "dawn volunteer service team". In 2018, the college has more than 350 formal volunteers, more than 4000 service objects, 75,000 hours of volunteer service and more than 50 large-scale volunteer service activities. Actively participate in the "Book drifting" activity sponsored by the school Youth Association, and the number of books collected has reached more than 1000 , accounting for more than half of the total collection of all departments participating in the activity.

In the aspect of supporting the construction of guarantee system, the long-term mechanism to guarantee the cultivation of "innovative" talents is formed through the establishment of annual assessment system, and stable policies and incentives are given to teachers to guide students' innovation, professors, especially famous academic leaders to teach undergraduates, and grassroots academic organizations to guide undergraduates' scientific and technological innovation teams.

\subsection{Continuous Improvement System}

The content of continuous improvement system includes continuous improvement of training objectives, graduation requirements, curriculum design, teaching content, curriculum outline and teaching process.

Talent training objective is the starting point and end point of talent training. The continuous improvement of training objective needs to be based on the orientation of school and professional talent training objective, combined with the development trend of new technology and new technology in the current industry, considering the change of talent demand in the industry, new requirements of comprehensive engineering education professional certification, and referring to the feedback of enterprise and expert research and discussion. With reference to the feedback of employers, graduates, students in school and teachers, a scientific and effective talent training goal will be formed.

The training objective of this major is to change from a compound engineering and scientific talents in the field of measurement and control to an international innovative and managerial talents with the scientific basis, professional technical knowledge, inertial navigation characteristics, the ability to solve complex engineering problems in the field of inertial navigation and measurement and control technology, and professional ethics and humanistic quality. Due to the continuous improvement of the training objectives, combined with the requirements of the latest standards of engineering education certification, the graduation requirements of the corresponding major increase the ability of solving complex engineering problems on the basis of the original requirements, and emphasize the non-technical factors such as engineering and society, environment and sustainable development. Combined with the characteristics of the 
major, the design and points of inertial navigation and measurement and control technology are particularly highlighted. Analysis and research ability.

As shown in Figure 1, the core of the continuous improvement system is to establish a set of training objective rationality evaluation mechanism, training objective achievement evaluation mechanism, graduation requirement evaluation mechanism, graduate quality tracking feedback mechanism, teaching conditions, management service quality evaluation mechanism, and teaching environment quality evaluation mechanism. Through the training objective rationality evaluation, training objective achievement evaluation, graduation It requires achievement evaluation, graduates, employers comprehensive evaluation, students, teachers comprehensive evaluation, curriculum objectives achievement evaluation, forming closed-loop feedback, and continuously improving training objectives, graduation requirements, curriculum system, faculty and support conditions.

\section{Summary}

Under the background of engineering education professional certification, to build an innovative talent training system of "measurement and control specialty", we need to adhere to the four in one goal concept system, training implementation system, training support system and continuous improvement system, and carry out the following work in accordance with the idea of "student-centered, results oriented":

1) Combining with the professional certification of engineering education and the training needs of "innovative" talents, determine the training objectives of "innovative" talents in measurement and control technology and instrument specialty. In this project, the innovation characteristics and innovation ability of students majoring in measurement and control technology and instruments are systematically studied, and the training objectives of this major are determined by comprehensive schools, professional positioning, professional characteristics, social evaluation and graduate feedback.

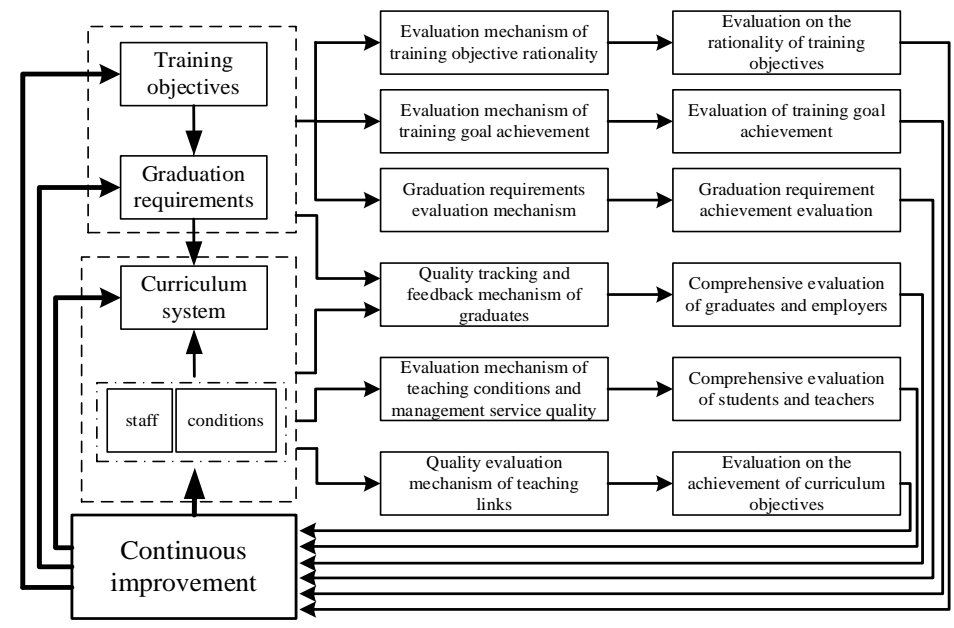

Figure 1. Construction block diagram of continuous improvement system. 
2) Based on the background of engineering education professional certification, the training concept of "innovative" talents in measurement and control technology and instrument specialty is condensed. The concepts of "student-centered", "training of ability to solve complex engineering problems" and "measuring the level of students with ability to solve complex engineering problems" in the certification work of engineering education are highly consistent with the training concept of innovative talents. The purpose of this project is to systematically analyze the relationship between innovative talents and engineering education talents training through research. The combination of the two forms a new training concept.

3) Design the training plan of "innovative" talents in measurement and control technology and instrument specialty, so that the "innovative" talents training can be implemented in the teaching process. Design a specific "innovative" talent training program for measurement and control technology and instrument specialty based on the certification standard of engineering education specialty, which involves the whole process from teaching plan, teaching link, curriculum system to teaching process, assessment and evaluation, and requires the feasibility and rationality of operation. This subject aims to establish specific implementation measures for "innovative" talent training through research.

4) To build a supporting system for "innovative" talents in measurement and control technology and instrument specialty, we should first work out a set of reasonable and feasible management system, safeguard measures and incentive measures, and then establish a "innovative" teaching staff. Carry out school enterprise cooperation and international cooperation, and improve the construction of innovation platform.

\section{Acknowledgements}

We gratefully acknowledge Education and teaching reform project of Heilongjiang Provincial Department of Education (Research on "innovative” personnel training system of "measurement and control technology and instrument" under the background of engineering education professional certification (Project No.: sigy20170508)) for generous financial support.

\section{Conflicts of Interest}

The authors declare no conflicts of interest regarding the publication of this paper.

\section{References}

Chen, A. H. (2018). Characteristics and Training Approaches of Innovative Engineering Science and Technology Talents. Higher Engineering Education Research, No. 12, 9-13.

Li, Z. Y., Zhu, H., Liu, Z. J., et al. (2013). Construction and Practice of Training System for Top Innovative Talents in Research Universities. Higher engineering education research, No. 5, 136-140. 
Liu, G. R., Qin, Z. Z., Huang, J. W., et al. (2014). Research and Practice of Engineering Application-Oriented Undergraduate Education Characteristics and Innovative Personnel Training System. Teaching of China University, No. 12, 39-41.

Qi, Y. G. (2016). In Depth Discussion on the Reform of University Innovative Personnel Training System. China higher education, No. 17, 12-15.

Shen, X. Q., Wang, Y. H., \& Kou, X. J. (2018). Construction and Practice of Innovative talent Training System Based on CDIO and Ncbe Concepts. Education and Teaching Forum, 367, 142-143.

Wang, J., \& Sun, R. (2017). Research on Some Problems in the Cultivation of High-Level Innovative Scientific and Technological Talents in China. Science of Science and Management of Science and Technology, 33, 165-173.

Wang, L. W. (2017). Construction of Innovation and Entrepreneurship Talents Training System Based on the Cooperation of University, Government, Business and Enterprise. Science and Technology Entrepreneurship Monthly, 30, 69-70.

Wu, H. (2016). The Enlightenment of Ivy League's Talent Training Concept to China's University Talent Training. Educational Exploration, No. 7, 148-150.

Xie, M., \& Miao, Q. (2011). Innovative Personnel Training Mode and Reference in American Universities. Journal of Southwest University for Nationalities, No. 3, 217-221.

Yin, X., \& Xi, F. R. (2015). Construction of Innovative and Entrepreneurial Talent Training System for College Students. China University Science and technology, No. 3, 75-77. 